\title{
Determinants and Mechanisms of Digital Financial Inclusion Development: Based on Urban-Rural Differences
}

\author{
Guang Liu ${ }^{1}$, Yunying Huang ${ }^{1, *(1)}$ and Zhehao Huang ${ }^{2}(\mathbb{D}$ \\ 1 School of Economics and Statistics, Guangzhou University, Guangzhou 510006, China; lg2013@gzhu.edu.cn \\ 2 Guangzhou Institute of International Finance, Guangzhou University, Guangzhou 510006, China; \\ zhehao.h@gzhu.edu.cn \\ * Correspondence: 2112064029@e.gzhu.edu.cn
}

Citation: Liu, G.; Huang, Y.; Huang, Z. Determinants and Mechanisms of Digital Financial Inclusion

Development: Based on Urban-Rural Differences. Agronomy 2021, 11, 1833. https://doi.org/10.3390/agronomy 11091833

Academic Editors: Paulina Rytkönen, Theodosia Anthopoulou, Karin Dahlström and Håkan Tunón

Received: 17 August 2021

Accepted: 10 September 2021

Published: 13 September 2021

Publisher's Note: MDPI stays neutral with regard to jurisdictional claims in published maps and institutional affiliations.

Copyright: (c) 2021 by the authors. Licensee MDPI, Basel, Switzerland. This article is an open access article distributed under the terms and conditions of the Creative Commons Attribution (CC BY) license (https:/ / creativecommons.org/licenses/by/ $4.0 /)$.

\begin{abstract}
The combination of digital finance and financial inclusion can better meet the needs of those who have little access to financial services. This paper investigated the differences in the determinants and mechanisms of digital financial inclusion development between urban and rural areas. The sample consists of 1607 counties in China from 2014 to 2019, and uses the fixed-effect model and panel threshold technique. The empirical results indicate that: (1) The industrial economy and governmental intervention are the common determinants of urban and rural digital financial inclusion development, in which the degree is different. At the same time, secondary education is only a determinant in rural areas. (2) Industrial upgrading and indirect finance play a mediating role in the determinants of digital financial inclusion, but indirect finance is only significant for urban areas. (3) There is a threshold effect in the financial development-digital financial inclusion relationship. Under different financial development levels, the determinants of urban and rural digital financial inclusion show the discrepancy. With the development of digital financial inclusion under the trend of promoting innovative digital finance in China, these findings are expected to enhance access to financial services in urban and rural areas for more inclusive and sustainable futures.
\end{abstract}

Keywords: digital financial inclusion; urban-rural differences; determinants; mechanisms; threshold effect

\section{Introduction}

Financial inclusion is a financial system wherein all economic agents have access to effective financial services, especially for underdeveloped areas and low-income people. A sound financial inclusion system is a necessary foundation for the improvement of the depth and breadth of finance. In the aftermath of the financial crisis, financial inclusion has become an important public policy priority, and thus had been set as an improving goal in more than 50 countries and regions worldwide by 2014. Financial inclusion refers to the "access to appropriate, low cost, fair and safe financial products, and services from mainstream service providers" [1]. The development of financial inclusion has great achievement all over the world, and the living environment of the poor is in the process of improving. The concept of financial inclusion was introduced in China in 2005, and the idea of developing financial inclusion was formally put forward in 2013. There is a strong association between the practice of financial inclusion and innovative digital finance in China. Digital financial inclusion experienced a great leap forward in development from 2011 to 2020 in China. The novel digital financial service as a representative of the fintech company could reduce the threshold and cost of financial services and expand the coverage of financial services through information technology and product innovation. Therefore, the novel digital financial service has become an important driving force and growth point of financial inclusion. There is a core and weak link in the improvement and development of the county financial inclusion system in China. The integration of digital technology and financial inclusion contributes to surmounting the financial exclusion of vulnerable 
groups in rural and county areas, such as farmers and small micro-enterprises in China. Digital financial inclusion could be invaluable in boosting economic growth and solving agricultural and rural development.

With the support of digital technology, financial inclusion has contributed significantly to reducing the cost of financial supply and improving the effectiveness of financial services. The Global Partners of Inclusive Finance (GPFI) advocates for the use of digital technology to promote financial inclusion. Moreover, the OECD highlighted the need for digital financial literacy. One of the most successful examples of digital money accelerated financial inclusion is Kenya's M-Pesa [2]. Based on the literature and the traditional financial inclusion indicators built by international organizations, combined with the new features of digital financial inclusion, Peking University Institute of Digital Finance and the fintech company Alibaba Ant Financial Service have constructed the Peking University Digital Financial Inclusion Index of China (PKU_DFIIC) [3]. The PKU_DFIIC is built from three dimensions: the coverage breadth of digital finance, the usage depth of digital finance, and the digitization level of financial inclusion. Existing research largely focuses on two areas: On the one hand, most scholars discuss the determinants of financial inclusion, while digital finance is discussed separately. Both financial inclusion and digital finance are indeed able to promote the development of areas excluded from financial services. On the other hand, several scholars have investigated the implementation effect of digital financial inclusion, such as narrowing the income gap and optimizing resource allocation in the financial market. To ensure digital financial inclusion development, it is crucial to understand the determinants and mechanisms better. The inefficient and uneven allocation of financial resources under the dual urban-rural economic structure has not been efficiently solved, which is the constraint of the rural vitalization. It is necessary to gain insight into the development status of digital financial inclusion, identify the bottlenecks and obstacles faced - which provide the basis for the formulation of relevant policies-and promote the sustainable development of digital financial inclusion. However, these points are neglected by most current existing research. Therefore, herein, it is urgently addressed how to promote digital financial inclusion in a timely and effective way under the dual urban-rural economic structure in regard to financial development. Meanwhile, the discrepancy in urban and rural areas for digital financial inclusion will help governmental and financial institutions to adjust the policies based on urban and rural status, contributing to financial efficiency and allocation. These findings suggest that further investigation is warranted. One objective of this investigation is to examine the determinants and mechanisms of digital financial inclusion development based on urban-rural differences. Another objective of this investigation is to examine the discrepancy of the urban and rural determinants under different financial development levels.

The main work and findings of this paper including the following. Based on the panel data of 1607 counties in China from 2014 to 2019, this paper investigated the discrepancies in the determinants and mechanisms of digital financial inclusion development between urban and rural areas by using the fixed-effect model and panel threshold technique. First, we investigate the discrepancy of urban-rural digital financial inclusion determinants more generally, rather than focusing on one particular economy. The industrial economy and governmental intervention are the common determinants of urban and rural digital financial inclusion development, in which the degree is different. At the same time, secondary education is only a determinant in rural areas. Second, we go a step further in the mechanisms of the discrepancy in the digital financial inclusion development between urban and rural areas. On the one hand, industrial upgrading plays a mediating role in the relationship between the industrial economy and digital financial inclusion, which, in rural areas, is much weaker than in urban areas. On the other hand, indirect finance plays a mediating role in the governmental intervention of urban digital financial inclusion, but this may be absent in rural areas. Third, there is a threshold effect in the financial development-digital financial inclusion relationship. The role of the industrial economy has been continuously improved through financial development. The promotional effect 
of governmental intervention in urban areas is blunted with the development of finance, which displays a tendency of decreasing first, and then increasing in rural areas. These findings are expected to make appropriate adjustments in the implementation of digital financial inclusion in urban and rural areas to improve the depth and coverage of digital financial inclusion.

The marginal contributions of this paper are as follows. First, most of the existing research examines financial inclusion and digital finance separately. Digital technology helps financial inclusion to better perform in promoting development in underdeveloped areas and for low-income people. Therefore, it is necessary to investigate digital financial inclusion. On this basis, we present the main results of the digital financial inclusion determinants and mechanisms. The development of rural digital financial inclusion should focus on talent cultivation and infrastructure construction. Second, we investigate the difference of the industrial economy, governmental intervention, and secondary education on urban and rural digital financial inclusion development. In addition, we also bring new light to the mechanisms of the industrial economy and governmental intervention. These findings fill the vacancy of the correlative research and provide recommendations for the development of digital financial inclusion. Third, the phenomenon of financial exclusion in the county environment is more obvious, and the demand for digital financial inclusion is great. The results of this paper have a stronger targeted policy by using county data to carry out empirical research. Moreover, when comparing the differences between urban and rural areas, it is conducive to overcome the issues presented by the dual urban-rural economic structure and enable the excluded people to enjoy financial services to escape poverty.

The remainder of the article is structured as follows. Section 2 is the literature review, which reviews the existing research. Section 3 lays out the research hypotheses and introduces the empirical model based on the analysis of the relationship between key variables. Section 4 contains a discussion of the empirical findings of the determinants of digital financial inclusion development, which is different in urban and rural areas. Section 5 further discusses mechanisms about the determinants of digital financial inclusion development, which varies between urban and rural areas. Section 6 provides conclusions and implications. Figure 1 shows the logic framework of this paper. 


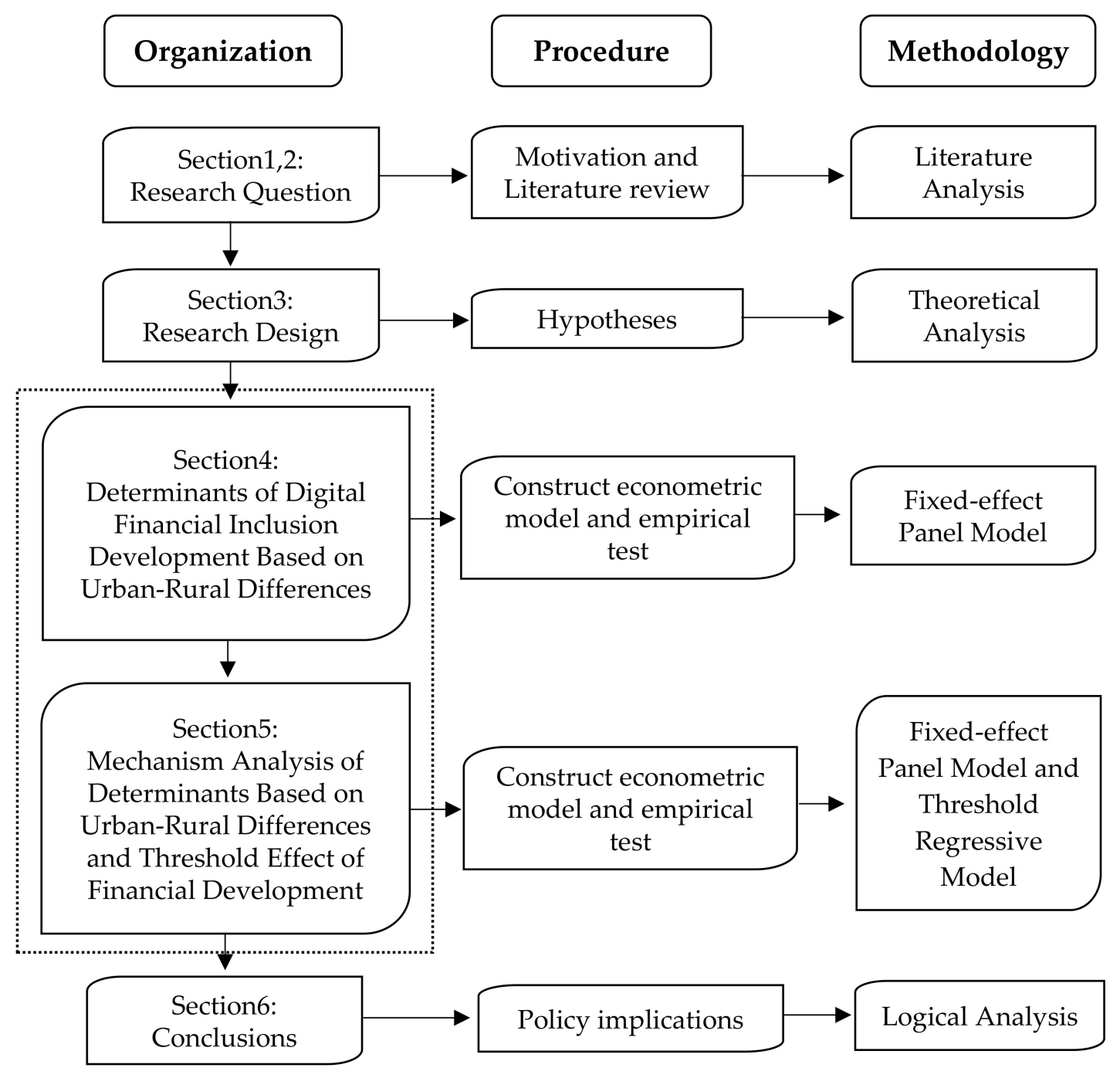

Figure 1. The logical framework of this paper.

\section{Literature Review}

The benefits of linking digital finance and financial inclusion are attracting the attention of the public to the number of advantages that digital technology advances and financial inclusion have for the population. On the one hand, digital finance can assist financial inclusion to operate much more effectively. Through detailed content analysis, it is evident that digital financial literacy can further set the stage for financial inclusion development [4]. Leong et al. shed light on how digital technology can improve the financial inclusion of previously excluded market segments [5]. Larios-Hernandez have exemplified how both blockchain and digital finance technology have the entrepreneurial motivation to seek opportunities for financially excluded individuals [6]. Information and Communication Technologies (ICT) could help to bridge the financial infrastructure gap by collaborating with the financial sector [7]. Mobile money services are expected to accelerate financial inclusion under sustainable business models [8]. However, in practice, greater use of digital finance may contribute to greater financial data inclusion rather than greater financial inclusion [9]. The practices of digital-based FI incorporate the poor into global strategies of capital accumulation, which is particularly apt to shaping financialized subjectivities [10]. On the other hand, digital financial inclusion may contribute to increasing economic efficiency for stakeholder groups. The expected benefits of digital financial inclusion can be fully realized by neglecting the cost of digital transactional platforms [11]. There are long-term positive effects for banking performance in the innovation of digital 
financial inclusion, such as lower costs and fewer bank branches [12]. A platform provided by digital finance facilitates increases in financial transactions, which subsequently generates higher tax revenue, benefiting governments that can then exert direct influence by orienting their activities [13,14]. Digital financial inclusion has diminished households ${ }^{\prime}$ ability to insure against transitory income shocks, partly because the online purchase may lead to the oversensitivity of consumption to income [15]. Through investigation, Kemal found that digital payment enables female beneficiaries to receive social cash securely and conveniently [16]. Development in digital financial inclusion also encourages a positive trend in foreign portfolio investment in the form of FDI [17,18]. Berger et al. examined the design and installation activities surrounding information communication technologies which, if implemented effectively, can provide quality financial services to the poor [19]. The innovation process of digital finance has been significantly accelerated, and digital financial inclusion has been evolving at a very high speed. There is no doubt that digital financial inclusion is a good access point for the future in the field of formal financial services for excluded and underserved populations. An effective digital financial inclusion program should be appropriate in the population, and should be delivered sustainably and affordably.

Existing research on digital financial inclusion focuses on determinants of policies, financial tools, government conduct, and socio-demographic characteristics. Policies that push forward information infrastructure development and financial sector reform could stimulate financial inclusion by promoting digital finance [7,20-23]. The digital revolution adds new layers to the material cultures of digital financial inclusion, offering the state new ways to expand the inclusion of the underprivileged [24]. P2P lending as a tool to popularize digital financial inclusion may unintentionally exclude some consumer segments due to the competitive nature of P2P platforms [21,25]. If the government and the financial sector could collaborate better, digital financial inclusion would be better due to technology adoption channels $[26,27]$. The increment effect of financial support and technological progress transit from high to low smoothly with the changes in government expenditure [28]. Digitizing government services and government cashless policies can help to promote digital financial inclusion in developing countries $[29,30]$. The rigid rules placed on digital finance have limited their ability and endangered commercial sustainability, thereby harming financial inclusion [31]. The humble and light-touch regulatory attitude of fintech regulation would promote innovation for improving digital financial inclusion [32] The contextual facilitators, like price benefits, network externalities, trust, and habit, drive mobile payment usage intention, which holds the potential for financial inclusion in developing economies [33]. There is a significant effect of socio-demographic characteristics on the use of digital financial services [34]. These research trends suggest that some studies have studied the determinants of digital financial inclusion. However, there has been barely any research that has analyzed the discrepancies in the determinants of urban and rural areas.

Under the dual urban-rural economic structure, there are great divergences in developing digital financial inclusion between urban and rural areas. The theories of digital technology overrepresent urban experiences, producing a gap in understanding of rural areas [35]. Zhang et al. found that digital financial inclusion is positively correlated with household income, and the positive effect in rural areas is larger than in urban areas, which indicates the benign distributive impact in rural China [36]. Factors hindering the innovation of digital financial inclusion were the reconfiguration of rural life, the dematerialization of cash, local and regional politics, and gender relations [37]. The disparity between the rural and urban dwellers is an issue as the use of digital financial services has not yet gained popularity, and most of the rural dwellers are not on the digital financial inclusion's radar for assisting financial institutions' increased customer reachability [38]. Similarly, digital financial inclusion in Kenya primarily reaches wealthier urban inhabitants who are already financially served, rather than serving rural inhabitants who are poor and underserved [39]. The chasm between urban-rural development leads to a better implementation 
of digital financial inclusion in urban areas, and less than expected implementation in rural areas. There are persistent and growing differences in data infrastructure quality between urban and rural areas [40]. Digital financial inclusion should improve the rural groups uncovered by financial inclusion and deepen the usage depth of the covered groups. The economy cannot grow fast without proper implementation of digital financial inclusion in rural areas. Although the digital economy contributed to the sector of the rural economy, stubborn social, economic, and territorial digital divides continue to create challenges that put remote rural home-based micro-businesses at risk of being left behind [41]. Moreover, there is a significant disparity among people of rural-urban areas in availing the services of the financial inclusion system in India, which has made great efforts to bring in underprivileged rural people to the mainstream financial system [42]. Titus observed that the sustainability of financial inclusion to rural dwellers in Nigeria is keeping with the mainstream for economic growth in any country [43]. The advancements in digital financial inclusion have a stabilizing impact on the banking industry, which is mainly driven by underserved adults who live in rural areas [44]. However, although a great number of literature has studied the discrepancy in the development of digital financial inclusion between urban and rural areas, so far, relatively little is known about the real determinants of the discrepancy.

\section{Research Design}

\subsection{Theoretical Analysis and Research Hypothesis}

The differences between urban and rural determinants of digital financial inclusion are mainly given expression through supply-push and demand-pull. In terms of supply-push, the discrepancies between urban and rural areas in the regional industrial economy, policy support, inclusive financial infrastructure construction, and so on contribute to the difference in the development of digital financial inclusion. The urban economy is dominated by modern industrial production, while the rural economy is dominated by a small-scale peasant economy. The urban industrial economy that is rather high is likely to boost regional economic development, thereby carrying the digital financial inclusion to a new and higher level. The proportion of the industrial economy in the rural small-scale peasant economy is relatively low, so it is difficult to play its role in boosting digital financial inclusion. The knotty problem in the rural industrial economy is a shortage of finances, which is caused by the small scale of the rural industry and weak anti-risk capability [45], which will hinder the growth of digital financial inclusion. China has a history of urban industry bias, which puts rural areas at a disadvantage of value squeezed. The stronger legal rights and more politically stable environment of urban areas are significantly associated with its greater digital financial inclusion [46]. The implementation effect of the policy in rural areas, which is intended for the development of digital financial inclusion, is not as good as expected. The commerciality and profit orientation of financial institutions, as the natural conflict of digital financial inclusion particularity, prefer to operate in urban areas where economic interests are easier to obtain than in rural areas. The decentralization of rural service objects conflicts with the pursuit of large-scale financial institutions, resulting in insufficient motivation for financial institutions to provide services in rural areas. The government plays a role in guiding the rational allocation of urban and rural financial resources to promote the development of digital financial inclusion as a result of these contradictions. The government will show different tendencies in policy formulation and implementation in urban and rural areas for eliminating the matter caused by the urban-rural dual structure. There is a discrepancy of development and difficulty faced due to the disparity of digital financial inclusion between urban and rural areas, and therefore, the action taken by the government will be adjusted accordingly.

In terms of demand-pull, the discrepancy between urban and rural areas in the quality of human capital, education level, and so on contribute to the different development of digital financial inclusion. It is convenient for the promotion and implementation of digital financial inclusion in urban areas with a high quality of human capital for more 
financial knowledge and lower financial exclusion. There is an impact on the profitability of agriculture businesses among the efficiency of structural capital usage and the stock of human capital [47]. With the improvement of education, urban residents put forward new requirements for the diversification and effectiveness of financial services. This is also conducive to the digital financial inclusion. At the same time, urban education resources are abundant, and thus more people receive higher education, while rural areas are dominated by secondary education. The diversity of household characteristics between urban and rural areas, such as household living conditions and asset accumulation, strongly affect the digital financial inclusion decision [48]. Based on the above analysis, this paper proposes the following hypothesis:

Hypothesis 1 (H1). The determinants of digital financial inclusion are different in urban and rural areas.

By upgrading industrial structure, the industrial economy has a significant and positive impact on digital financial inclusion, which found a discrepancy between urban and rural areas. The impact of industrial upgrading on digital financial inclusion in urban areas resulted mainly from the following aspects: (1) Maximizing the comparative advantages of financial talents and the adsorption capacity of financial resources, and expanding the development potential of the urban financial market. In industrial economy development, industrial upgrading is the force pushing the urban social capital flow, which gets more innovative resources together. This may provide the opportunity window and market tension for digital financial inclusion. (2) Propelling the fund turnaround in the socioeconomic sector, raising the driving forces for the development and potential for the growth of urban digital financial inclusion. Rationalization and advancement of the urban industry structure appeals to new demands for financial services, which are unable to enjoy traditional credit services. (3) Coordinated regional development and cost reduction produced by industrial upgrading to develop urban digital financial inclusion [49]. However, the impact of industrial upgrading on digital financial inclusion takes another form in rural areas. The Chinese modern agriculture industrial system is in infancy, and is a part of the small-scale peasant economy. This system is a hard nut to crack for industrial upgrading. It is feasible for China to promote economic development through hastening the optimization and upgrading of its rural industrial structure [50,51], as well as the agricultural finance industry. The optimization of the industrial structure reaches the rural economy by scaling up, which will energize rural digital financial inclusion. Industrial upgrading is a relatively slow process in rural areas, where residents guard land resources and take agriculture as the main revenue generator. In particular, industrial economy development before industrial structural upgrading is still based on the expansion of construction land at the cost of the farmlands encroached [52]. This would lead to the industrial economy having a less positive impact on rural digital financial inclusion through the upgrading of the industrial structure.

Through indirect finance, governmental intervention has a significant and positive impact on digital financial inclusion, which may perform differently in urban and rural areas. The government can intervene in a country's banking system through government ownership and government involvement [53]. Urban areas have better financial infrastructure and economic growth as compared to rural areas, which brings into full play the role of governmental intervention in indirect finance. Better financial infrastructure has a significant role in digital financial inclusion. On the one hand, the government intervenes in the distribution of urban credit and has an important impetus for the credit supply of commercial banks. On the other hand, the government intervened in banks to increase long-term credit, which provides stable financial support for the growth of digital financial inclusion. Most the rural inhabitants who are poor and underserved need high-level, comprehensive, and diversified financial services primarily through loans. Rural clients are less attractive to financial intermediaries due to the implementation of microfinance and weakness in the design that usually comes with small and short-term loans that are not suit- 
able for agriculture [54]. Moreover, a limited knowledge and awareness of financial credit will increase the risk of financial institutions, resulting in lessened bank inefficiency with a view of increasing the non-performing loans [55]. The increasing of the non-performing loan is not conducive to the development of rural digital financial inclusion. There is a mismatch between the supply and demand of financial services in rural areas, and digital financial inclusion cannot fully energize the market. Based on the above analysis, this paper puts forward the following hypothesis:

Hypothesis 2 (H2). The mechanisms of industrial economy and governmental intervention on digital financial inclusion development are different in urban and rural areas.

Moreover, the existing evidence also demonstrates that the extent of influence of digital financial inclusion determinants relate to financial development, which shows a discrepancy in urban and rural areas. The extent of the impact that the industrial economy and governmental intervention have on digital financial inclusion would not be alike according to different financial development stages. Given the significant inequality in financial development between urban and rural areas in China, this relationship in rural areas might probably be quite different from that of urban areas. The industrial economy has given greater attention to industrial innovation strategies, to which the contribution from rapid financial growth has become increasingly important [56]. What motivates the rapid progress of industry and the promotion of industrial upgrading is financial development as an essential factor. The constant market bolster has a greater influence on the industrial economy to promote digital financial inclusion. Financial development gives back to industrial efficiency, and industrial efficiency adds fuel to digital financial inclusion. This interactive process will be different as a result of the industrial economy gap between urban and rural areas. Moreover, with the development of urban digital financial inclusion in places with better financial development, the government would reduce its intervention to reducing the crowding-out effect. The development of rural finance is lower than that of urban finance; therefore, the demand for rural digital financial inclusion for government guidance is greater than that of urban areas. Digital financial inclusion is built around existing financial development, and governmental intervention mainly occurs in the primary stage. Based on the above analysis, the following hypothesis is proposed:

Hypothesis 3 (H3). There is a threshold effect in the financial development-digital financial inclusion determinants relationship in urban and rural areas.

Figure 2 shows the assumptions of $\mathrm{H} 1, \mathrm{H} 2$ and $\mathrm{H} 3$ in this paper.

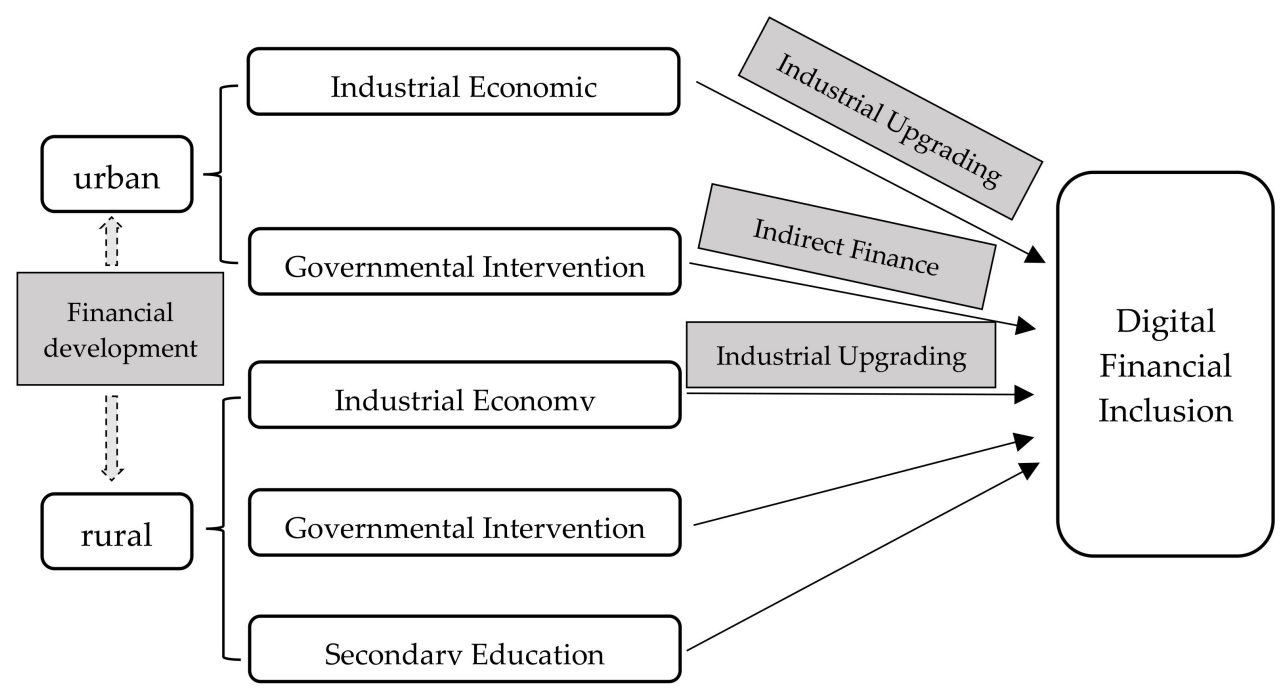

Figure 2. Determinants and mechanisms of digital financial inclusion based on urban and rural areas. 


\subsection{Methods}

To test the hypothesis outlined in the previous section, we argue that the fixed-effect model is particularly well suited to examine the determinants of digital financial inclusion as follows:

$$
D F I_{i t}=\alpha_{0}+\alpha_{1} \operatorname{Ind}_{i t}+\alpha_{2} \operatorname{Gov}_{i t}+\alpha_{3} E d u_{i t}+\lambda X_{i t}+\rho_{i}+\omega_{t}+\varepsilon_{i t}
$$

where $D F I_{i t}$ is the level of digital financial inclusion, $I n d_{i t}$ is the county's industrial economy, $G o v_{i t}$ is the degree of governmental intervention, $E d u_{i t}$ is the secondary education, $X$ is a vector of controls (economic development, information level, and medical construction), $\rho_{i}$ represents the controlling individual county, $\omega_{t}$ is controlling for time fixed effects, $\varepsilon_{i t}$ is an error term, $i=1, \ldots, N$ represents the county, and $t=1, \ldots, T$ represents the index time.

Previous analysis shows that the industrial economy has a significant and positive impact on digital financial inclusion through the upgrading of the industrial structure. In the process of the industrial economy, industrial upgrading is the force pushing digital financial inclusion, which propels the rural economy by scaling up and energizing urban digital financial inclusion. The mediating model is carried out as follows [57,58]:

$$
\begin{gathered}
\operatorname{DFI}_{i t}=\alpha_{0}+\alpha_{1} \operatorname{Ind}_{i t}+\alpha_{2} X_{i t}+\rho_{i}+\omega_{t}+\varepsilon_{i t} \\
\operatorname{Iup}_{i t}=\beta_{0}+\beta_{1} \text { Ind }_{i t}+\beta_{2} X_{i t}+\rho_{i}+\omega_{t}+\mu_{i t} \\
D F I_{i t}=\lambda_{0}+\lambda_{1} \text { Ind }_{i t}+\lambda_{2} \text { Iup }_{i t}+\lambda_{3} X_{i t}+\rho_{i}+\omega_{t}+\xi_{i t}
\end{gathered}
$$

where $I u p_{i t}$ is the level of industrial upgrading. In the mediating model, Equation (2) is the first step regression, which comes from model 1 , where $\alpha_{1}$ measures the total effect of the industrial economy on digital financial inclusion development. Equation (3) is the second step regression, where $\beta_{1}$ measures the effect of the industrial economy on the industrial upgrading mediating variable, which means that the industrial economy has explained the industrial upgrading if significant. Equation (4) is the third step regression, where $\lambda_{2}$ measures the effect of the industrial upgrading mediating variable on digital financial inclusion development after controlling the industrial economy independent variable. If in the parameter estimation results of Equation (4), $\lambda_{1}$ and $\lambda_{2}$ are significant, have the positive symbols, and the value of $\lambda_{1}$ is lower than $\alpha_{1}$, that is, there is a certain degree of mediating effect. Moreover, if $\lambda_{1}$ is insignificant, but $\lambda_{2}$ is significant, this represents that industrial upgrading plays the role of a full mediator.

In addition, through indirect finance, governmental intervention has a significant and positive impact on digital finance. Urban areas with better financial infrastructure and economic growth - which brings into full play the role of governmental intervention in indirect finance- - has a significant role in digital financial inclusion. Most of the rural inhabitants demand greater digital financial inclusion, not limited to loans. For the limitations of rural areas, the operational risk of financial institution increases, which is not conducive to the development of rural digital financial inclusion. The mediating model is carried out as follows:

$$
\begin{gathered}
D F I_{i t}=\alpha_{0}+\alpha_{1} \operatorname{Gov}_{i t}+\alpha_{2} X_{i t}+\rho_{i}+\omega_{t}+\varepsilon_{i t} \\
\operatorname{Inf}_{i t}=\beta_{0}+\beta_{1} \operatorname{Gov}_{i t}+\beta_{2} X_{i t}+\rho_{i}+\omega_{t}+\mu_{i t} \\
D F I_{i t}=\lambda_{0}+\lambda_{1} \operatorname{Gov}_{i t}+\lambda_{2} \operatorname{Inf}_{i t}+\lambda_{3} X_{i t}+\rho_{i}+\omega_{t}+\xi_{i t}
\end{gathered}
$$

where $I n f_{i t}$ represents the indirect finance. In the mediating model, Equation (5) is the first step regression, which comes from model 1 , where $\alpha_{1}$ measures the total effect of the governmental intervention on digital financial inclusion development. Equation (6) is the second step regression, where $\beta_{1}$ measures the effect of the governmental intervention on the indirect finance mediating variable, which means that the governmental intervention has explained the indirect finance, if significant. Equation (7) is the third step regression, 
where $\lambda_{2}$ measures the effect of the indirect finance mediating variable on digital financial inclusion development after controlling the governmental intervention independent variable. In the meaning of the parameter estimation results of Equation (7), $\lambda_{1}$ and $\lambda_{2}$ are similar to Equation (4).

We assess the extent of influence of digital financial inclusion determinants, which is related to financial development. Consequently, we use the panel threshold regression approach suggested by Hansen [59] to explore the nonlinear behavior of determinants of digital financial inclusion regarding financial development. Based on the threshold regression, we refine the basic model and take the following form:

$$
\begin{gathered}
D F I_{i t}=c+\rho_{1} \operatorname{Ind}_{i t}\left[\text { Fin } \leq \gamma_{1}\right]+\rho_{2} \operatorname{Ind}_{i t}\left[\gamma_{1}<\text { Fin } \leq \gamma_{2}\right]+\rho_{3} \operatorname{Ind}_{i t}\left[\text { Fin }>\gamma_{3}\right] \\
+\varphi_{1} \operatorname{Gov}_{i t}\left[\text { Fin } \leq \gamma_{1}\right]+\varphi_{2} \operatorname{Gov}_{i t}\left[\gamma_{1}<\text { Fin }^{\prime} \gamma_{2}\right] \\
+\varphi_{3} \text { Gov }_{i t}\left[\text { Fin }>\gamma_{3}\right]+\alpha E d u_{i t}+\lambda X_{i t}+\varepsilon_{i t}
\end{gathered}
$$

where the level of financial development (Fin) is the threshold variable used to split the sample into groups and $\gamma$ is the unknown threshold parameter. What needs to be noted is that all models are conducted in the urban and rural samples separately to compare the differences.

\subsection{Variable Description and Data Sources}

To estimate the model, we employ panel data of 1607 counties in China from 2014-2019. This paper selects the digital financial inclusion (DFI) as the dependent variable, constructed by the Peking University Institute of Digital Finance and the fintech company Alibaba Ant Financial Service. Digital financial inclusion captures the three dimensions of coverage breadth, usage depth, and digitization level. The explanatory variables are set as follows: (i) industrial economy (Ind), calculated with the added value of secondary industry and taking the logarithm; (ii) governmental intervention (Gov), calculated with local financial expenditures in local GDP; and (iii) secondary education (Edu), calculated with the number of students in secondary school and taking the logarithm. We select two mediating variables, respectively: industrial upgrading (Iup) and indirect finance (Inf). The former is the proportion of the added value of the secondary and tertiary industries in GDP, and the latter is loan balance per capita. In addition, the level of financial development (Fin) is the threshold variable, and the measure of banking sector development is employed as a measure of financial development [60].

Economic development (Eco), informatization level (Inf), and medical construction (Med) are included in the model as control variables. Economic development is calculated by per capita GDP and taking the logarithm, which has a fundamental role in digital financial inclusion development. Informatization level is calculated with telephone penetration, which satisfied the prerequisites to adopt digital financial inclusion. Medical construction is calculated by the number of hospital beds per capita, which reflects the allocation of the public resources offered by the government between urban and rural areas. Stata 16 software is used for data processing. The meaning and sources of the variables are summarized in Table 1.

Table 2 reports descriptive statistics of the above variables in urban and rural samples. Using the OECD regional classification, this paper divides counties into urban and rural areas according to population density. Counties with a population density higher than 500 people per square kilometer are defined as urban, and those with a lower population density are defined as rural. It can be seen that all variables of sample counties are different from different angles. Based on this, we analyze the determinants and mechanisms of digital financial inclusion, which finds a discrepancy between the urban and rural areas. 
Table 1. Variable data source.

\begin{tabular}{ccl}
\hline Variable & Abbr. & Source \\
\hline Digital Financial Inclusion & DFI & Digital Financial Inclusion Index of China \\
Industrial Economy & Ind & China Statistical Yearbook (County Level) \\
Governmental Intervention & Gov & China Statistical Yearbook (County Level) \\
Secondary Education & Edu & China Statistical Yearbook (County Level) \\
Economic Development & Eco & China Statistical Yearbook (County Level) \\
Informatization Level & Inf & China Statistical Yearbook (County Level) \\
Medical Construction & Med & China Statistical Yearbook (County Level) \\
Industrial Upgrading & Iup & China Statistical Yearbook (County Level) \\
Indirect Finance & Inf & China Statistical Yearbook (County Level) \\
Financial Development & Fin & China Statistical Yearbook (County Level) \\
\hline
\end{tabular}

Table 2. Descriptive statistics.

\begin{tabular}{|c|c|c|c|c|}
\hline & Unit & Items & Urban & Rural \\
\hline $\mathrm{N}$ & - & & 2214 & 7428 \\
\hline \multirow{2}{*}{ DFI } & \multirow{2}{*}{-} & Mean & 89.08 & 84.4271 \\
\hline & & Std & 23.21 & 24.61741 \\
\hline \multirow{2}{*}{ Ind } & \multirow{2}{*}{ ratio } & Mean & 13.93 & 12.76742 \\
\hline & & Std & 0.92 & 1.127755 \\
\hline \multirow{2}{*}{ Gov } & \multirow{2}{*}{ ratio } & Mean & 16.93 & 32.85194 \\
\hline & & Std & 9.43 & 23.80552 \\
\hline \multirow{2}{*}{ Edu } & \multirow{2}{*}{$\ln$ (person) } & Mean & 10.37 & 9.558112 \\
\hline & & Std & 0.65 & 0.817146 \\
\hline \multirow{2}{*}{ Eco } & \multirow{2}{*}{$\ln (\mathrm{RMB} /$ person $)$} & Mean & 4.55 & 3.675358 \\
\hline & & Std & 4.34 & 3.38737 \\
\hline \multirow{2}{*}{ Inf } & \multirow{2}{*}{ ratio } & Mean & 983.87 & 939.2462 \\
\hline & & Std & 911.15 & 874.7456 \\
\hline \multirow{2}{*}{ Med } & \multirow{2}{*}{ bed/person } & Mean & 39.68 & 41.81459 \\
\hline & & Std & 15.61 & 17.88123 \\
\hline \multirow{2}{*}{ Iup } & \multirow{2}{*}{ ratio } & Mean & 85.05 & 79.17214 \\
\hline & & Std & 8.52 & 10.76238 \\
\hline \multirow{2}{*}{ Inf } & \multirow{2}{*}{ RMB/person } & Mean & 9.89 & 9.866019 \\
\hline & & Std & 0.90 & 0.681127 \\
\hline \multirow{2}{*}{ Fin } & \multirow{2}{*}{ ratio } & Mean & 64.40 & 74.82114 \\
\hline & & Std & 39.89 & 46.36051 \\
\hline
\end{tabular}

\section{Econometric Examination of Determinants of Digital Financial Inclusion Development of Urban-Rural Areas}

\subsection{Results of Parameter Estimation}

Table 3 presents the results from the fixed-effect model to explain the determinants of digital financial inclusion. Column (1) of Table 3 shows the regression results of the urban digital financial inclusion, and column (2) shows the results of the rural digital financial inclusion. In the case of significant results, the coefficients are somewhat different in magnitude and directions, which is related to the extent of the determinants of digital financial inclusion between urban and rural areas. 
Table 3. Results of benchmark regression grouped sample of urban and rural areas.

\begin{tabular}{ccc}
\hline & (1) & $(\mathbf{2})$ \\
& Urban & Rural \\
\hline \multirow{2}{*}{ Ind } & $9.118^{* * *} 1$ & $2.730^{* * *}$ \\
& $(11.038)$ & $(8.287)$ \\
Gov & $0.082^{*}$ & $0.041^{* * *}$ \\
& $(1.883)$ & $(3.840)$ \\
Edu & -0.190 & $1.704 * * *$ \\
& $(-0.213)$ & $(3.218)$ \\
Eco & $-3.955^{* * *}$ & $-0.999^{* * *}$ \\
& $(-18.043)$ & $(-9.446)$ \\
Inf & $0.001^{* * *}$ & $0.001^{* * *}$ \\
& $(2.682)$ & $(6.688)$ \\
Med & -0.003 & $0.025^{* *}$ \\
& $(-0.126)$ & $(2.381)$ \\
Individual control & Yes & Yes \\
Time control & Yes & Yes \\
cons & $-58.518^{* * *}$ & -6.133 \\
$\mathrm{~N}$ & $(-4.120)$ & $(-0.937)$ \\
$\mathrm{R}^{2}$ & 2214 & 7428 \\
$\mathrm{~F}$ & 0.946 & 0.946 \\
\end{tabular}

$1, *, * *, * * *$ significant at $10 \%$ level, $5 \%$ level, and $1 \%$ level, respectively. The values in brackets are T-values.

The parameter estimation result of the industrial economy is positive and statistically significant at the $1 \%$ level, which consisted in both urban and rural areas. However, coefficient magnitude reflects the extent of the impact of the industrial economy on the development of digital financial inclusion. This finding shows that the industrial economy can effectively promote digital financial inclusion development, which tends to impact urban areas more positively than rural areas. The parameter estimation result of the governmental intervention is positive and statistically significant between urban and rural areas. The coefficient magnitude is different, implying that governmental intervention can have a more positive effect in urban areas. The parameter estimation result of secondary education is positive and statistically significant in rural areas, but it is negative and not significant in urban areas. This implies that secondary education would boost the rural digital financial inclusion development, but this determinant may be absent in urban digital financial inclusion development.

The empirical findings are consistent with the relationships in determinants of digital financial inclusion that are reported in the literature. We start with analyzing the industrial economy to urban-rural digital financial inclusion development first. The urban economy is based on modern industrial production, while the rural economy is based on a small-scale peasant economy. China has a history of urban industry bias that results in the economic disadvantage of the rural industry. The urban industrial economy, which is relatively high, would advance the digital financial inclusion to a higher level. In contrast, the proportion of the industrial economy in rural areas is relatively low, so it is difficult to play its role in boosting digital financial inclusion. The analysis then proceeded to the impact of governmental intervention on urban and rural digital financial inclusion development. The complete organizational setting in urban areas makes the implementation effect of the policy better. The prevalence of financial exclusion in rural areas forces the financial institutions to consider risk tradeoffs. This exclusion needs considerable guidance from the government. However, governmental intervention may result in a greater redistribution effect in rural areas than in urban areas, and may lead to further erosion of the welfare of vulnerable rural groups, which may be detrimental to digital financial inclusion development. Finally, we found a discrepancy in secondary education on digital financial inclusion between urban and rural areas. Based on the empirical results, secondary education plays a significant role in promoting rural digital financial inclusion, but has a negligible effect 
in urban areas. The reason why this may have been the case is that, the higher the level of secondary education, the more conducive it is to promoting rural residents' access to formal credit, and thus effectively improves the effectiveness of digital financial inclusion. However, this effect is less evident in urban areas, which could be due to the fact that higher education resources are more abundant.

\subsection{Robustness Test}

To assess the reliability of benchmark regression, this section performs a robustness check. In the first set of robustness checks, as shown in columns (1) and (2) of Table 4, we winsorize the top and bottom $1 \%$ of explanatory variables. Considering that the deviation in data statistics will lead to abnormal values, we exclude outliers to maintain the robustness of the results. The magnitude and direction of coefficients are consistent with the benchmark regression, indicating that the industrial economy and governmental intervention are the common determinants of urban and rural digital financial inclusion development, although the degree is different. At the same time, secondary education is only a determinant in urban areas. Then, using the variable of the lag one-phase of the explanatory variable, this could, in part, diminish inverse causal relationships. As can be seen column (3) and (4) of Table 4, the overall results show that the existing estimation results are reliable, which further illustrates that the determinants of digital financial inclusion between urban and rural areas are robust. Table 4 reports the results from the robustness test.

Table 4. Results of the robustness test.

\begin{tabular}{ccccc}
\hline \multirow{2}{*}{ Item } & \multicolumn{2}{c}{ Winsorize } & \multicolumn{2}{c}{ Lag One-Phase } \\
\cline { 2 - 5 } & $\mathbf{( 1 )}$ & $\mathbf{( 2 )}$ & $\mathbf{( 3 )}$ & $\mathbf{( 4 )}$ \\
\cline { 2 - 5 } & Urban & Rural & Urban & Rural \\
\hline \multirow{2}{*}{ Ind } & $9.106^{* * *}$ & $3.473^{* * *}$ & $5.312^{* * *}$ & $3.126^{* * *}$ \\
& $(10.596)$ & $(10.015)$ & $(5.013)$ & $(8.281)$ \\
Gov & $0.124^{* *}$ & $0.025^{* *}$ & $0.116^{*}$ & $0.056^{* * *}$ \\
& $(2.470)$ & $(2.036)$ & $(1.881)$ & $(4.745)$ \\
Edu & -0.453 & $1.447^{* * *}$ & -0.312 & $1.844^{* * *}$ \\
& $(-0.493)$ & $(2.724)$ & $(-0.315)$ & $(3.250)$ \\
Eco & $-3.893^{* * *}$ & $-1.725^{* * *}$ & $-2.414^{* * *}$ & $-0.708^{* * *}$ \\
& $(-16.510)$ & $(-13.426)$ & $(-11.596)$ & $(-7.359)$ \\
Inf & $0.001^{* * *}$ & $0.002^{* * *}$ & $0.002 * * *$ & $0.001^{* * *}$ \\
& $(4.190)$ & $(8.808)$ & $(4.189)$ & $(3.107)$ \\
Med & 0.002 & $0.052^{* * *}$ & -0.018 & $0.020^{*}$ \\
Individual control & $(0.061)$ & $(4.298)$ & $(-0.686)$ & $(1.817)$ \\
Time control & Yes & Yes & Yes & Yes \\
_cons & Yes & Yes & Yes & Yes \\
& $-57.762^{* * *}$ & $-12.266^{*}$ & 9.925 & 7.173 \\
$\mathrm{~N}$ & $(-3.897)$ & $(-1.846)$ & $(0.567)$ & $(1.001)$ \\
$\mathrm{R}^{2}$ & 2214 & 7428 & 1845 & 6190 \\
$\mathrm{~F}$ & 0.944 & 0.949 & 0.894 & 0.910 \\
& 2787.466 & $1.0 \times 10^{4 *}$ & 1239.910 & 4970.213 \\
\hline
\end{tabular}

$1 *, * *, * * *$ significant at $10 \%$ level, $5 \%$ level, and $1 \%$ level, respectively. The values in brackets are T-values.

To solve the endogeneity problem that could be driven by unobservable local and economic characteristics, this paper performed the IV-2SLS estimation. The variable of the lag one-phase could partly diminish inverse causal relationships. We take Ind_lag1, Gov_lag1, and Edu_lag1 as the instrumental variables of the industrial economy, governmental intervention, and secondary education to verify the determinants of digital financial inclusion development. The results obtained by instrumental variables are consistent with the benchmark regression. The regression coefficient of the instrumental variable is significantly larger than the benchmark regression in rural areas. This is mainly because 
the instrumental variable solves the endogenous problem of the rising rural determinants and the development of digital financial inclusion in the same direction. There may be some unobservable economic factors in the estimation of rural areas. Table 5 reports the results from IV-2SLS estimation to solve the endogeneity problem.

Table 5. Results of the endogeneity problem.

\begin{tabular}{ccc}
\hline & $\begin{array}{c}(\mathbf{1}) \\
\text { Urban }\end{array}$ & $\begin{array}{c}(\mathbf{2}) \\
\text { Rural }\end{array}$ \\
\hline \multirow{2}{*}{ Ind } & $11.986^{* * * 1}$ & $8.526^{* * *}$ \\
& $(4.630)$ & $(7.999)$ \\
Gov & $0.209^{*}$ & $0.222^{* * *}$ \\
& $(1.413)$ & $(3.976)$ \\
Edu & -1.552 & $6.208^{* * *}$ \\
Eco & $(-0.357)$ & $(3.147)$ \\
& $-4.089^{* * *}$ & $-1.504^{* * *}$ \\
Inf & $(-9.545)$ & $(-8.232)$ \\
& $0.002^{* * *}$ & $0.001 * * *$ \\
Med & $(3.446)$ & $(4.216)$ \\
Individual control & -0.024 & $0.020^{*}$ \\
Time control & $(-0.876)$ & $(1.691)$ \\
Cons & Yes & Yes \\
N & -64.250 & Yes \\
Wald & $(-1.166)$ & $-106.177^{* * *}$ \\
\hline
\end{tabular}

$1 *, * * *$ significant at $10 \%$ level, $5 \%$ level, and $1 \%$ level, respectively. The values in brackets are T-values.

\section{Further Discussion}

5.1. Mechanisms Analysis of Determinants of Digital Financial Inclusion Development of Urban-Rural Areas

This section explored possible mechanisms by which the industrial economy and governmental intervention affect digital financial inclusion between urban and rural areas. We first analyzed that industrial upgrading plays a mediating role in the relationship between the industrial economy and digital financial inclusion. Then, we discuss that indirect finance is a mediating variable through which governmental intervention affects digital financial inclusion.

\subsubsection{Mechanisms Analysis of the Industrial Economy}

The development of the industrial economy pertains to industrial upgrading, which gives an impetus to the digital financial inclusion development. According to Equations (2) to (4) of Table 6, the regression results for which industrial upgrading is selected as the mediating variable through which the industrial economy affects digital financial inclusion development. The first three columns represent the urban areas; the results in rural areas are given in the last three columns of this table. The results in the second column show that the coefficient of the impact of the industrial economy on industrial upgrading in urban areas is significantly positive, indicating that the industrial economy has a positive impact on industrial upgrading. Meanwhile, after controlling the variable of industrial upgrading, the coefficient of the impact of the industrial economy on digital financial inclusion is still significantly positive. The value of the coefficient is lower than the benchmark regression, indicating that urban industrial upgrading has a certain mediating effect. The mediating effect of the industrial economy on rural digital financial inclusion through industrial upgrading is similar, though the extent of the mediating effect is different. The result of the Sobel mediating effect test shows that the effect of industrial upgrading as a mediating variable is significant, at $50.34 \%$ in urban areas, and yet $22.01 \%$ in rural areas, implying that 
the effect of the industrial economy on digital financial inclusion is through the promotion of industrial upgrading, which in rural areas is much weaker than in urban areas.

Table 6. Mechanisms analysis of industrial economy.

\begin{tabular}{|c|c|c|c|c|c|c|}
\hline \multirow{3}{*}{ Item } & \multicolumn{3}{|c|}{ Urban } & \multicolumn{3}{|c|}{ Rural } \\
\hline & DFI & Iup & DFI & DFI & Iup & DFI \\
\hline & (1) & (2) & (3) & (4) & (5) & (6) \\
\hline Ind & $9.118^{* * * 1}$ & $7.936^{* * *}$ & $4.528^{* * *}$ & $2.730 * * *$ & $7.521^{* * *}$ & $2.129^{* * *}$ \\
\hline Iup & - & - & $0.578^{* * *}$ & - & - & $0.080^{* *}$ \\
\hline $\begin{array}{l}\text { Control } \\
\text { variables }\end{array}$ & Yes & Yes & Yes & Yes & Yes & Yes \\
\hline _cons & $-78.863^{* * *}$ & $-37.338^{* * *}$ & $-28.308^{* *}$ & $42.498^{* * *}$ & $-6.808^{* *}$ & $43.042^{* * *}$ \\
\hline $\mathrm{N}$ & 2214 & 2214 & 2214 & 7428 & 7428 & 7428 \\
\hline $\mathrm{R}^{2}$ & 0.9546 & 0.9657 & 0.9559 & 0.9532 & 0.9616 & 0.9533 \\
\hline
\end{tabular}

$1 *, * *, * *$ significant at $10 \%$ level, $5 \%$ level, and $1 \%$ level, respectively.

As expected, the result is consistent with the hypothesis that industrial upgrading plays a mediating role in the relationship between the industrial economy and digital financial inclusion, but to a different extent between urban and rural areas. Several reasons may be responsible for this discrepancy. The urban industrial economy is relatively concentrated, maximizes the social capital flow, and pools innovative resources by industrial upgrading. At the same time, even though it is feasible to promote economic development through hastening the optimization and upgrading of its rural industrial structure [50], a low proportion of the industry as well as slow process industrial upgrading in rural areas may lead to the finding that the mediating effect is not as good as that of urban areas. The focus and effect of industrial upgrading in urban and rural areas are likely to be differential by the urban-rural dual structure. Moreover, industrial upgrading appeals to new demands for digital financial inclusion that originally developed differently in urban and rural areas, which will also give rise to the discrepancy.

\subsubsection{Mechanisms Analysis of Governmental Intervention}

The governmental intervention on digital financial inclusion is delivered mainly through the promotion of an indirect financial system. To resolve the conflict between digital financial inclusion and financial institutions, the government intervenes in the distribution of the credit and supply of financial services. Based on Equations (5) to (7), Table 7 reports the result of indirect finance as a mediating variable. The first three columns represent the urban areas; the results in rural areas are given in the last three columns of this table. The result in the second column shows that governmental intervention has a significant impact on indirect finance in urban areas, which indicates that governmental intervention can effectively promote financial institutions' service. The finding in the third column shows that the coefficient of the impacts of the governmental intervention on digital financial inclusion is still significantly positive in urban areas, but slightly reduced as compared with the result in the benchmark regression. This means that indirect finance is a mediating variable through which governmental intervention affects digital financial inclusion in urban areas. The result of the Sobel mediating effect test also supports the result [61]. The mediating effect of indirect finance accounts for $11.95 \%$ of the total effect of urban governmental intervention. However, one difference is worth noting in rural areas, from column (5), which is that the regression coefficient of governmental intervention is not significant in rural areas. This may imply that indirect finance would not be a mediating variable through which governmental intervention affects digital financial inclusion in rural areas. 
Table 7. Mechanisms analysis of governmental intervention.

\begin{tabular}{ccccccc}
\hline & \multicolumn{3}{c}{ Urban } & \multicolumn{3}{c}{ Rural } \\
\cline { 2 - 7 } Item & DFI & Inf & DFI & DFI & Inf & DFI \\
\cline { 2 - 7 } & $\mathbf{( 1 )}$ & $\mathbf{( 2 )}$ & $\mathbf{( 3 )}$ & $\mathbf{( 4 )}$ & $\mathbf{( 5 )}$ & $\mathbf{( 6 )}$ \\
\hline Gov & $0.082^{*}$ & $0.002^{* *}$ & $3.938^{* * *}$ & $0.041^{* * *}$ & 0.000 & $4.330^{* * *}$ \\
Inf & - & - & $0.072^{*}$ & - & - & $0.041^{* *}$ \\
Control & Yes & Yes & Yes & Yes & Yes & Yes \\
variables & & & & & & \\
cons & $-78.863 * * *$ & $4.952 * * *$ & $-90.787^{* * *}$ & $42.498^{* * *}$ & $9.938^{* * *}$ & -0.530 \\
$\mathrm{~N}$ & 2214 & 2214 & 2214 & 7428 & 7428 & 7428 \\
$\mathrm{R}^{2}$ & 0.9546 & 0.9761 & 0.9552 & 0.9532 & 0.9404 & 0.9541 \\
\hline
\end{tabular}

$1 *, * *, * * *$ significant at $10 \%$ level, $5 \%$ level, and $1 \%$ level, respectively.

It is worth mentioning that indirect finance plays a mediating role in the governmental intervention on urban digital financial inclusion, but this is absent in rural areas. The development of urban financial infrastructure and the economy are relatively better, and the effect of the governmental intervention in urban digital financial inclusion development through indirect financial systems would be better. For rural residents who are excluded or underserved by traditional finance, the need for financial service is high-level, comprehensive, and diversified, primarily, which requires the participation of digital financial inclusion. The design of microfinance mismatches the characteristics of agricultural production systems, resulting in financial intermediaries being less attractive to rural clients [54]. The governmental intervention in rural digital financial inclusion development, only on an increase, cannot exert its full function as a promoting effect. To address the difficulties of rural digital financial inclusion development, the first issue to address is the shortage of financial infrastructure and practitioners. Further guidance to solving the inherent drawbacks of rural financial product design is a method worth trying.

\subsection{Threshold Effect of Financial Development}

The threshold estimation of financial development in the determinants of digital financial inclusion uses Equation (8) and 300 Bootstrap replications. Table 8 reports the results of the threshold estimation of the grouped samples of urban and rural areas. We chose financial development as the threshold variable. Both the urban and rural sample passed the test at a significant level of $1 \%$ under the single threshold test and the double threshold test, but failed to pass the triple threshold test. Therefore, the model is set as a double threshold model. Then, we further analyze as such using the double threshold model. The threshold estimation of rural areas is bigger than urban areas, implying that determinants of rural digital financial inclusion are needed to exceed the higher financial development threshold than urban areas to have a certain change in the impact on the digital financial inclusion development. The above results embody that determinants of rural digital financial inclusion are relatively stable under the influence of financial development. This may be directly related to the relatively modest rate of rural financial development and the complicated circumstances associated with it. The development of urban digital financial inclusion is more sensitive to financial development. Now that the existence of a threshold has been determined, the next question addresses how financial development affects determinants of digital financial inclusion development. 
Table 8. Threshold estimation of the grouped sample of urban and rural areas.

\begin{tabular}{|c|c|c|c|c|c|c|}
\hline $\begin{array}{l}\text { Threshold } \\
\text { Variables }\end{array}$ & $\begin{array}{l}\text { Number of } \\
\text { Thresholds }\end{array}$ & $\mathbf{F}$ & $\mathbf{P}$ & Conclusion & $\begin{array}{l}\text { Threshold } \\
\text { Estimation }\end{array}$ & $\begin{array}{c}\text { 95\% Confidence } \\
\text { Interval }\end{array}$ \\
\hline \multirow{3}{*}{$\begin{array}{l}\text { Urban financial } \\
\text { development }\end{array}$} & One & 313.84 & 0.0000 & $\begin{array}{l}\text { Reject the null } \\
\text { hypothesis }\end{array}$ & 54.6697 & $(54.2477,54.7200)$ \\
\hline & Two & 134.08 & 0.0000 & $\begin{array}{c}\text { Reject the null } \\
\text { hypothesis }\end{array}$ & $\begin{array}{l}56.8872 \\
41.5935 \\
\end{array}$ & $\begin{array}{l}(56.7134,57.1059) \\
(29.1103,41.9348)\end{array}$ \\
\hline & Three & 104.14 & 1.0000 & $\begin{array}{c}\text { Accept the null } \\
\text { hypothesis }\end{array}$ & - & - \\
\hline \multirow{3}{*}{$\begin{array}{l}\text { Rural financial } \\
\text { development }\end{array}$} & One & 731.33 & 0.0000 & $\begin{array}{c}\text { Reject the null } \\
\text { hypothesis }\end{array}$ & 68.9634 & $(68.6887,69.0998)$ \\
\hline & Two & 502.63 & 0.0000 & $\begin{array}{c}\text { Reject the null } \\
\text { hypothesis }\end{array}$ & $\begin{array}{l}70.3303 \\
50.7740 \\
\end{array}$ & $\begin{array}{l}(70.1397,70.4942) \\
(50.1943,50.9848)\end{array}$ \\
\hline & Three & 298.56 & 1.0000 & $\begin{array}{l}\text { Accept the null } \\
\text { hypothesis }\end{array}$ & - & - \\
\hline
\end{tabular}

The empirical results are reported in Table 9. We access the statistical significance of the regime-dependent industrial economy and governmental intervention coefficients, where both the industrial economy and governmental intervention are positive and statistically significant determinants of digital financial inclusion development. On the one hand, the role of the industrial economy in promoting the digital financial inclusion development has been continuously improved if financial development is more than the threshold. This is because the magnitude of the increase in rural areas is larger than urban areas. On the other hand, the promotional effect of governmental intervention on digital financial inclusion development in urban areas is blunted if financial development is more than the threshold. It should be noted that this phenomenon has differing presentations in rural areas. As the financial development crosses over the first threshold, this promotion is weakened. However, as financial development crossed over the second threshold, this promotion is enhanced rather than weakened.

Table 9. Results of panel threshold estimation of grouped sample of urban and rural areas.

\begin{tabular}{ccc}
\hline \multirow{2}{*}{ Item } & $\mathbf{( 1 )}$ & $(\mathbf{2})$ \\
\cline { 2 - 3 } & Urban & Rural \\
\hline \multirow{2}{*}{ Ind_1 } & $22.105^{* * * 1}$ & $1.806^{*}$ \\
& $(9.56)$ & $(1.70)$ \\
Ind_2 & $24.138^{* * *}$ & $3.585^{* * *}$ \\
& $(10.27)$ & $(3.34)$ \\
Ind_3 & $25.878^{* * *}$ & $4.958^{* * *}$ \\
& $(10.85)$ & $(4.56)$ \\
Gov_1 & $2.315^{* * *}$ & $0.666^{* * *}$ \\
& $(9.96)$ & $(12.68)$ \\
Gov_2 & $1.532^{* * *}$ & $0.502^{* * *}$ \\
& $(8.33)$ & $(11.58)$ \\
Gov_3 & $1.208^{* * *}$ & $0.505^{* * *}$ \\
Control variables & $(9.98)$ & $(14.36)$ \\
cons & Yes & Yes \\
N & -360.430 & $-38.055^{*}$ \\
$\mathrm{R}^{2}$ & $(-8.98)$ & $(-1.78)$ \\
\end{tabular}

\footnotetext{
$1 *, * * *$ significant at $10 \%$ level, $5 \%$ level, and $1 \%$ level, respectively. The values in brackets are T-values.
}

The empirical findings align with a non-linear relationship between the industrial economy and digital financial inclusion within different financial developments discussed 
in the above analysis. The industrial economy contributed to rapid financial growth, which has become increasingly important [56]. A growing impact of the industrial economy on digital financial inclusion is financial development growth, which is simultaneously mutually reinforced among financial development and the industrial economy. This has jointly driven the comprehensive promotion of digital financial inclusion functions. Generally speaking, the urban industrial economy is relatively high compared with rural areas, which may lead to the marginal promotion of urban digital financial inclusion development, which is expected to diminish as finance grows. The industrial upgrading that pertains to financial development is found to help reduce farmland conversion [62], which can help contribute to the rural economic without damaging agricultural production. Rural financial development stimulates the industrial economy, which in turn benefits the development of digital financial inclusion in rural areas. With the evolution of financial development, there are significant changes in the pattern of rural living and production. It is necessary to develop rural digital financial inclusion through boosting the industrial economy in facing financial development, which can respond to potential rural demands and expand local entrepreneurship activities. There are more constraints in the urban industrial economy than in the rural industrial economy. Therefore, after the financial development shifts, the changes in the impact of digital financial inclusion development are not as significant as that in rural areas.

The reason for the non-linear relationship between governmental intervention and digital financial inclusion development, and the discrepancy between urban and rural areas might help the government to adjust to the actual conditions of urban-rural areas. In the early stage of financial development, governmental intervention resulted in faster wealth accumulation and relaxed borrowing constraints in the future [63], which was similar in both urban and rural areas. However, with the improvement of the financial development to advancing urban market dynamism, the government guidance in digital financial inclusion is weakening. Rural observations are noteworthy. In a scenario where the financial development in rural areas is higher than the second threshold, governmental intervention will exert a higher positive impact on digital financial inclusion. This scenario could lead to a further expansion of the wealth redistribution between the rich and poor, where rural financial development is highly advanced, which will lead to the poor in rural areas to experience reduced welfare and an exclusion from financial services. In such cases, the government is likely to take more steps to give preferential policies and several subsidies to the poor in rural areas that will eliminate the adverse effects of high financial development in rural areas.

\section{Conclusions and Implication}

This study provided new evidence on determinants and mechanisms of digital financial inclusion, and further explored the discrepancy in urban and rural areas. By combing the data of Peking University Digital Financial Inclusion Index of China and China Statistical Yearbook (County Level), we performed empirical analyses on differences in the determinants and mechanisms of digital financial inclusion development between urban and rural areas. The empirical results indicated that these determinants and mechanisms differ in urban and rural areas, and that there is a financial development threshold in the determinants. Through using the fixed-effect model and panel threshold technique, the following conclusions can be drawn.

First, the determinants of digital financial inclusion are different in urban and rural areas, as follows: (1) The industrial economy can effectively promote digital financial inclusion development, which tends to impact urban areas more positively than rural areas. The urban industrial economy, which is relatively high, would advance digital financial inclusion to a higher level. At the same time, though the proportion of the industrial economy in rural areas is relatively low, its role in boosting digital financial inclusion is less than that of urban areas. (2) Governmental intervention has a catalytic role in advancing digital financial inclusion, which tended to be pronounced in urban 
areas. The more complete organizational setting in urban areas makes the implementation effect of the policy better. The vulnerable rural group who has little access to financial services is much larger and more complicated, which may explain why the effect of governmental intervention in digital financial inclusion is less than in urban areas. (3) Secondary education would boost the rural digital financial inclusion development, which may be absent in urban areas. This is more conducive to promoting rural residents' access to formal credit who are educated to the secondary level. However, this effect is less evident in urban areas where higher education resources are more abundant. There also exist other determinants of digital financial inclusion development, where there are no observations available for some local and economic characteristics. There should be many determinants of digital financial inclusion, so that the research is worthy of further expansion.

Second, the mechanisms of the industrial economy and governmental intervention on digital financial inclusion development are different in urban and rural areas. On the one hand, industrial upgrading plays a mediating role in the relationship between the industrial economy and digital financial inclusion, which in rural areas is much weaker than in urban areas. This may be in correlation with the economic structure of urban and rural areas. The urban industrial economy is relatively concentrated, maximizes the social capital flow, and pools innovative resources through industrial upgrading. While a low proportion of the industry and slow process industrial upgrading in rural areas may lead to this mediating effect, it is not as good as that of urban areas. On the other hand, indirect finance plays a mediating role in the governmental intervention of urban digital financial inclusion, but this may be absent in rural areas. This might be related to the different requirements of people who have little access to finance in urban and rural areas. It is relatively good in urban financial infrastructure and economic development to play a guiding role in digital financial inclusion through the indirect financial system. If the governmental intervention in rural digital financial inclusion development focuses only on increasing loans, whose design mismatches the characteristics of agricultural production, it cannot exert its full function as a promoting effect. We believe that further investigation in mechanisms of determinants helped us do our work much better. In future research, we will study in-depth the mechanisms that may be overlooked in this paper.

Finally, there is a threshold effect in the financial development-digital financial inclusion determinants relationship in urban and rural areas. The determinants of rural digital financial inclusion are relatively stable under the influence of financial development, manifested in two ways. For one, the role of the industrial economy in promoting the digital financial inclusion development has been continuously improved with the financial development. The magnitude of the increase in rural areas is larger than urban areas. For another, the promotional effect of governmental intervention on digital financial inclusion development in urban areas is blunted with the development of finance, which displays a tendency of decreasing first and then increasing in rural areas. This phenomenon is likely associated with the following reasons. There are more constraints in the urban industrial economy than in the rural industrial economy. Therefore, after the financial development shifts, the changes in the impact of digital financial inclusion development are not as significant as that in rural areas. With the improvement of financial development, the vitality of the urban market has increased significantly, and the guidance of the government in digital financial inclusion is weakening. The government is likely to take more steps to give preferential policies and several subsidies to the poor in rural areas that may eliminate the adverse redistribution effects of high financial development in rural areas.

Knowing the determinants and mechanisms of digital financial inclusion and the discrepancy in urban and rural areas are important in ensuring the effectiveness of digital financial inclusion for growth. The conclusions of this paper can be used as a reference for governments to adjust policies of digital financial inclusion based on urban and rural status. Due to the difficulties with county-level data collection, several other factors we do not incorporate may be correlated with digital financial development. These potentially important issues can serve as future research topics. It is vital to consider potential 
limitations and other determinants that may affect the development of digital financial inclusion. Moreover, to make the investigation more persuasive, more research methods are needed in the further study, as there are likely not enough in this paper. Given that the determinants of digital financial inclusion development may have spatial interaction and a spillover effect, one interesting aspect would be to analyze the impact of digital financial inclusion development on surrounding counties. Further refinement of vulnerable population groups with little access to financial services is required to explore their discrepancy of digital financial inclusion. More research is needed to confirm the findings and further advance the research direction. For these issues, we leave these for future research.

Author Contributions: Conceptualization, G.L., Y.H., and Z.H.; data curation, Y.H.; formal analysis, G.L. and Y.H.; funding acquisition, G.L.; investigation, Y.H. and Z.H.; methodology, G.L., Y.H., and Z.H.; project administration, G.L. and Z.H.; resources, G.L. and Y.H.; software, Y.H.; supervision, G.L. and Z.H.; validation, G.L. and Z.H.; visualization, Y.H.; writing—original draft, Y.H.; writing—review and editing, G.L., Y.H., and Z.H. All authors have read and agreed to the published version of the manuscript.

Funding: This research was funded by National Social Science Fund Project, China (No: 19BJY249).

Data Availability Statement: Not applicable.

Acknowledgments: The authors would like to thank the anonymous reviewers' clear and detailed feedback.

Conflicts of Interest: The authors declare no conflict of interest.

\section{References}

1. Varghese, G.; Viswanathan, L. Normative perspectives on financial inclusion: Facts beyond statistics. J. Public Aff. 2018, 18, e1829. [CrossRef]

2. Kusimba, S.; Yang, Y.; Chawla, N. Hearthholds of mobile money in western Kenya. Econ. Anthropol. 2016, 3, 266-279. [CrossRef]

3. Guo, F.; Wang, J.; Wang, F.; Kong, T.; Zhang, X.; Cheng, Z. Measuring China's Digital Financial Inclusion: Index Compilation and Spatial Characteristics. China Econ. Q. 2020, 19, 1401-1418.

4. Goyal, K.; Kumar, S. Financial literacy: A systematic review and bibliometric analysis. Int. J. Consum. Stud. 2021, 45, 80-105. [CrossRef]

5. $\quad$ Leong, C.; Tan, B.; Xiao, X.; Tan, F.T.C.; Sun, Y. Nurturing a FinTech ecosystem: The case of a youth microloan startup in China. Int. J. Inf. Manag. 2017, 37, 92-97. [CrossRef]

6. Larios-Hernandez, G.J. Blockchain entrepreneurship opportunity in the practices of the unbanked. Bus. Horiz. 2017, 60, 865-874. [CrossRef]

7. Mushtaq, R.; Bruneau, C. Microfinance, financial inclusion and ICT: Implications for poverty and inequality. Technol. Soc. 2019, 59, 101154. [CrossRef]

8. David-West, O.; Iheanachor, N.; Umukoro, I. Sustainable business models for the creation of mobile financial services in Nigeria. J. Innov. Knowl. 2020, 5, 105-116. [CrossRef]

9. Malady, L. Consumer protection issues for digital financial services in emerging markets. Bank. Financ. Law Rev. 2016, 31, 389-401. [CrossRef]

10. Kear, M. Governing Homo Subprimicus: Beyond Financial Citizenship, Exclusion, and Rights. Antipode 2013, 45, 926-946. [CrossRef]

11. Ozili, P.K. Impact of digital finance on financial inclusion and stability. Borsa Istanb. Rev. 2018, 18, 329-340. [CrossRef]

12. Scott, S.V.; Van Reenen, J.; Zachariadis, M. The long-term effect of digital innovation on bank performance: An empirical study of SWIFT adoption in financial services. Res. Policy 2017, 46, 984-1004. [CrossRef]

13. Kemfert, C.; Schmalz, S. Sustainable finance: Political challenges of development and implementation of framework conditions. Green Financ. 2019, 1, 237-248. [CrossRef]

14. Manyika, J.; Lund, S.; Singer, M.; White, O.; Berry, C. Digital finance for all: Powering inclusive growth in emerging economies. McKinsey Glob. Inst. 2016, 9, 1-15.

15. Lai, J.N.T.; Yan, I.K.M.; Yi, X.J.; Zhang, H. Digital Financial Inclusion and Consumption Smoothing in China. China World Econ. 2020, 28, 64-93. [CrossRef]

16. Kemal, A.A. Mobile banking in the government-to-person payment sector for financial inclusion in Pakistan*. Inf. Technol. Dev. 2019, 25, 475-502. [CrossRef]

17. Li, Z.H.; Huang, Z.H.; Dong, H. The Influential Factors on Outward Foreign Direct Investment: Evidence from the? The Belt and Road? Emerg. Mark. Financ. Trade 2019, 55, 3211-3226. [CrossRef] 
18. Qamruzzaman, M.; Wei, J.G. Do financial inclusion, stock market development attract foreign capital flows in developing economy: A panel data investigation. Quant. Financ. Econ. 2019, 3, 88-108. [CrossRef]

19. Berger, E.; Nakata, C. Implementing Technologies for Financial Service Innovations in Base of the Pyramid Markets. J. Prod. Innov. Manag. 2013, 30, 1199-1211. [CrossRef]

20. Blauw, S.; Franses, P.H. Off the Hook: Measuring the Impact of Mobile Telephone Use on Economic Development of Households in Uganda using Copulas. J. Dev. Stud. 2016, 52, 315-330. [CrossRef]

21. Loureiro, Y.K.; Gonzalez, L. Competition against common sense Insights on peer-to-peer lending as a tool to allay financial exclusion. Int. J. Bank Mark. 2015, 33, 605-623. [CrossRef]

22. Shaikh, A.A.; Glavee-Geo, R.; Karjaluoto, H. Exploring the nexus between financial sector reforms and the emergence of digital banking culture-Evidences from a developing country. Res. Int. Bus. Financ. 2017, 42, 1030-1039. [CrossRef]

23. Suri, T. Mobile Money. Annu. Rev. Econ. 2017, 9, 497-520. [CrossRef]

24. Gabor, D.; Brooks, S. The digital revolution in financial inclusion: International development in the fintech era. New Polit. Econ. 2017, 22, 423-436. [CrossRef]

25. Rogers, C.; Clarke, C. Mainstreaming social finance: The regulation of the peer-to-peer lending marketplace in the United Kingdom. Br. J. Polit. Int. Relat. 2016, 18, 930-945. [CrossRef]

26. Ajide, F.M. Financial inclusion in Africa: Does it promote entrepreneurship? J. Financ. Econ. Policy 2020, 12, 687-706. [CrossRef]

27. Mouna, A.; Jarboui, A. Understanding the link between government cashless policy, digital financial services and sociodemographic characteristics in the MENA countries. Int. J. Sociol. Soc. Policy 2021. [CrossRef]

28. Liao, G.K.; Drakeford, B.M. An analysis of financial support, technological progress and energy efficiency: Evidence from China. Green Financ. 2019, 1, 174-187. [CrossRef]

29. Aboal, D.; Tacsir, E. Innovation and productivity in services and manufacturing: The role of ICT. Ind. Corp. Chang. 2018, 27, 221-241. [CrossRef]

30. Skiter, N.N.; Ketko, N.V.; Rogachev, A.F.; Gushchina, E.G.; Vitalyeva, E.M. Institutional poverty as one of the main threats to the digital economy. Int. J. Sociol. Soc. Policy 2021, 41, 15-23. [CrossRef]

31. Yu, T.; Shen, W. Funds sharing regulation in the context of the sharing economy: Understanding the logic of China's P2P lending regulation. Comput. Law Secur. Rev. 2019, 35, 42-58. [CrossRef]

32. Tsai, C.H.; Peng, K.J. The FinTech Revolution and Financial Regulation: The Case of Online Supply-Chain Financing. Asian J. Law Soc. 2017, 4, 109-132. [CrossRef]

33. Pal, A.; Herath, T.; De, R.; Rao, H.R. Contextual facilitators and barriers influencing the continued use of mobile payment services in a developing country: Insights from adopters in India. Inf. Technol. Dev. 2020, 26, 394-420. [CrossRef]

34. Lyons, A.; Grable, J.; Zeng, T. Impacts of Financial Literacy on Loan Demand of Financially Excluded Households in China. SSRN 2017, 3075003. [CrossRef]

35. Young, J.C. Rural digital geographies and new landscapes of social resilience. J. Rural Stud. 2019, 70, 66-74. [CrossRef]

36. Zhang, X.; Zhang, J.J.; Wan, G.H.; Luo, Z. Fintech, Growth and Inequality: Evidence from China's Household Survey Data. Singap. Econ. Rev. 2020, 65, 75-93. [CrossRef]

37. Van Klyton, A.; Tavera-Mesias, J.F.; Castano-Munoz, W. Innovation resistance and mobile banking in rural Colombia. J. Rural Stud. 2021, 81, 269-280. [CrossRef]

38. Agwu, M.E. Can technology bridge the gap between rural development and financial inclusions? Technol. Anal. Strateg. Manag. 2021, 33, 123-133. [CrossRef]

39. Nan, W.X.; Markus, M.L. Is Inclusive Digital Innovation Inclusive? An Investigation of M-Shwari in Kenya. In Information and Communication Technologies for Development: Strengthening Southern-Driven Cooperation as a Catalyst for Ict4d, Pt I; Nielsen, P., Kimaro, H.C., Eds.; Springer: Cham, Switzerland, 2019; Volume 551, pp. 460-471.

40. Salemink, K.; Strijker, D.; Bosworth, G. Rural development in the digital age: A systematic literature review on unequal ICT availability, adoption, and use in rural areas. J. Rural Stud. 2017, 54, 360-371. [CrossRef]

41. Philip, L.; Williams, F. Remote rural home based businesses and digital inequalities: Understanding needs and expectations in a digitally underserved community. J. Rural Stud. 2019, 68, 306-318. [CrossRef]

42. Bansal, S. Perspective of Technology in Achieving Financial Inclusion in Rural India. Procedia Econ. Financ. 2014, 11, 472-480. [CrossRef]

43. Titus Freeman Ifeanyi, N. Relationship between Financial Inclusion and Economic Growth in Nigerian Rural Dwellers. Int. J. Small Bus. Entrep. Res. 2015, 3, 17-27.

44. Danisman, G.O.; Tarazi, A. Financial inclusion and bank stability: Evidence from Europe. Eur. J. Financ. 2020, 26, 1842-1855. [CrossRef]

45. Li, Y.H.; Westlund, H.; Liu, Y.S. Why some rural areas decline while some others not: An overview of rural evolution in the world. J. Rural Stud. 2019, 68, 135-143. [CrossRef]

46. Allen, F.; Demirguc-Kunt, A.; Klapper, L.; Peria, M.S.M. The foundations of financial inclusion: Understanding ownership and use of formal accounts. J. Financ. Intermediation 2016, 27, 1-30. [CrossRef]

47. Ovechkin, D.V.; Romashkina, G.F.; Davydenko, V.A. The Impact of Intellectual Capital on the Profitability of Russian Agricultural Firms. Agronomy 2021, 11, 286. [CrossRef] 
48. Naz, M.; Iftikhar, S.F.; Fatima, A. Does financial inclusiveness matter for the formal financial inflows? Evidence from Pakistan. Quant. Financ. Econ. 2020, 4, 19-35. [CrossRef]

49. Li, G.D.; Fang, C.L. Analyzing the multi-mechanism of regional inequality in China. Ann. Reg. Sci. 2014, 52, 155-182. [CrossRef]

50. Hao, Y.; Wang, L.O.; Zhu, L.Y.; Ye, M.J. The dynamic relationship between energy consumption, investment and economic growth in China's rural area: New evidence based on provincial panel data. Energy 2018, 154, 374-382. [CrossRef]

51. Li, T.; Li, X. Does structural deceleration happen in China? Evidence from the effect of industrial structure on economic growth quality. Natl. Account. Rev. 2020, 2, 155-173. [CrossRef]

52. Zhu, F.; Zhang, F.; Ke, X. Rural industrial restructuring in China's metropolitan suburbs: Evidence from the land use transition of rural enterprises in suburban Beijing. Land Use Policy 2018, 74, 121-129. [CrossRef]

53. Cornett, M.M.; Guo, L.; Khaksari, S.; Tehranian, H. The impact of state ownership on performance differences in privately-owned versus state-owned banks: An international comparison. J. Financ. Intermed. 2010, 19, 74-94. [CrossRef]

54. Marr, A. Effectiveness of Rural Microfinance: What We Know and What We Need to Know. J. Agrar. Chang. 2012, 12, 555-563. [CrossRef]

55. Hosen, M.; Broni, M.Y.; Uddin, M.N. What bank specific and macroeconomic elements influence non-performing loans in Bangladesh? Evidence from conventional and Islamic banks. Green Financ. 2020, 2, 212-226. [CrossRef]

56. Liu, F.C.; Simon, D.F.; Sun, Y.T.; Cao, C. China's innovation policies: Evolution, institutional structure, and trajectory. Res. Policy 2011, 40, 917-931. [CrossRef]

57. Baron, R.M.; Kenny, D.A. The moderator-mediator variable distinction in social psychological research: Conceptual, strategic, and statistical considerations. J. Pers. Soc. Psychol. 1986, 51, 1173-1182. [CrossRef]

58. Yang, C.; Li, T.; Albitar, K. Does Energy Efficiency Affect Ambient PM2.5? The Moderating Role of Energy Investment. Front. Environ. Sci. 2021, 9. [CrossRef]

59. Hansen, B.E. Sample splitting and threshold estimation. Econometrica 2000, 68, 575-603. [CrossRef]

60. Law, S.H.; Singh, N. Does too much finance harm economic growth? J. Bank. Financ. 2014, 41, 36-44. [CrossRef]

61. Li, F.; Yang, C.; Li, Z.; Failler, P. Does Geopolitics Have an Impact on Energy Trade? Empirical Research on Emerging Countries. Sustainability 2021, 13, 5199. [CrossRef]

62. Li, Y.H.; Chen, C.; Wang, Y.F.; Liu, Y.S. Urban-rural transformation and farmland conversion in China: The application of the environmental Kuznets Curve. J. Rural Stud. 2014, 36, 311-317. [CrossRef]

63. Itskhoki, O.; Moll, B. Optimal Development Policies with Financial Frictions. Econometrica 2019, 87, 139-173. [CrossRef] 